\title{
Equity Sensitivity Predicting Job Satisfaction and Commitment
}

\author{
Dr. Sarwat Sultan \\ Frasat Kamran
}

\begin{abstract}
The study aimed at investigating and comparing the differences in job satisfaction and commitment reported by three types of employees; benevolent, equity sensitive, and entitled. A sample of 300 employees (150 males and 150 females) aged 25 to 55 years was taken from different organizations of Multan. Equity Sensitive Scale, and Job Satisfaction Scale, Organizational Commitment Scale were used. Results indicated that benevolent experience significantly greater degrees of job satisfaction and commitment as compared to other types of employees. Results pertaining to gender differences showed that female benevolent and male entitled were more satisfied and committed with their jobs, while no gender differences were found for equity sensitive group.
\end{abstract}

Keywords: Benevolent, Equity Sensitive, Entitled, Inequity, Job Attitudes.

\section{Introduction}

People react differently to the situations when they get more compensation than what is justified or lower compensation than what is justified. Some of the individuals favor to be over-rewarded and some accept established fairness while some prefer underreward. This concept is recognized as Equity Sensitivity which has very effectively prophesized opinions and actions in various discriminatory states of affairs (O'Neill \& Mone, 1998). Based on the concept of equity sensitivity, the workers on various measures of equity sensitivity are grouped into three categories: Benevolent, Equity Sensitive, and Entitled. Recent studies have found an association between these categories and core elements of an organization like as job performance, gratification, effort, company loyalty, and turnover (King \& Miles, 1994).

Benevolent are those employees who always prefer their own cost/reward proportions to be smaller than those of their coworkers. The benevolent seem to be satisfied with less compensated. Benevolent to a greater extent withstand the state of affairs in which they are less honored and paid. Though they do not strive to be less compensated, they are supposed less probably to react (at least openly), particularly while they are put in a state of affairs in which they are less compensated (King, Miles, \& Day. 1993). Equity Sensitive employees choose their own input/outcome proportion expectant with even balance with those of their coworkers. As far as the results for their contributions are concerned they like to be involved in a state of fairness when making comparison to their partners. If an Equity Sensitive's input/output proportional relationship is not in

Dr. Sarwat Sultan is Chairperson Dept. of Applied Psychology, Bahauddin Zakariya University, Multan, sarwatsultan@hotmail.com

Frasat Kamran is affiliated with the Institute of Management Sciences, Bahauddin Zakariya University, Multan. 
harmony with others doing same work, the individual would be committed to perform tasks to attain their incentives return into harmony with others.

Entitled are those who choose their input/output ratio expectant greater compared to their referents. Furthermore, entitled like to get compensation more than what they deserve. Entitled are considered to feel smaller amount of inconsistency when they get more than due compensation and feel more discontent when get compensation that is less than what they deserve (Messick \& Cook, 1983).

Paid workers strive to keep fairness in the contribution they put to their occupation and the result that they get from it opposed to the assumed contributions and results of others (Adams, 1965). Construct of Equity suggests people comprehending as even getting compensation that is less than what they deserve or getting compensation that is more than what they deserve will feel discomfort, and that this mental suffering leads them to make attempts to mend fairness among the relation. It emphasizes on deciding the doubt of question about fair division of resources among employees. Equity is evaluated by making comparisons between the inputs such as time, devotion, hard work, responsibility, competence, adaptability and so on while outputs include affection, state of feeling safety, regard for employee benefit, acknowledgement, accountability, feeling of success, admiration, and gratefulness of every worker within the organizations (Mueller \& Clarke, 1998).

Employees experiencing inequity feel discomfort. The more the unfair situations, the more the discomfort they experience. According to equity theory, both the individuals getting more or less than actual complain discomfort. One getting too much may experience responsibility of wrongdoing or disappointment, and the other one getting too little may feel annoyed or disgraced (Walster, Traupmann, \& Walster, 1978). The persons feel themselves in an unfair association try to eradicate their mental suffering by returning equity back to previous position. The higher the unfairness, the higher the mental suffering individuals report and the higher they seek to bring back fairness. People might react like as decreasing their contributions, for instance, not putting more effort, or increasing their outcomes for instance ask for a arousal. Eventually, the person can decide to get out of the state of affairs by starting work in another organization or leaving the organization (Walster, et al., 1978).

In today's business environmental characteristics such as globalization and highercompetition, companies are being compelled to confidently believe in higher rate of production from their employees while at the same time keeping incentive scheme of controlling cost. Therefore, this novel kind of under-reward conditions should well be applied to present job framework keeping in view the decreasing number of employees, flattening and job enlargement (Ball, Trevino, \& Sims. 1994)

Recent researches have been found to try to confirm the substantial differences among Benevolent, Equity Sensitive and Entitled. Huseman, Hatfield, \& Miles (1987) investigated the equity sensitivity as independent for job satisfaction. They discovered that in reaction to under-reward situations, Entitled indicate lower gratification when compared with Equity Sensitive or Benevolent whereas Benevolent show greater amount of satisfaction 
with their jobs as compared to the other two categories. King et al. (1993) also discovered the Benevolent undergraduate students as expressing low degree of discomfort than Entitled when confronted by the under or over-reward situations. They also discovered that entitled give more value to money and benevolent put more value to features of job itself that bring significance for them. In addition, O'Neill and Mone (1998) studied equity sensitivity as a mediator factor in association between one's efficacy beliefs and organizational behaviors like job performance, gratification, loyalty and turn over. Authors reported benevolent show a correlation of job gratification, performance, and commitment with efficacy beliefs.

Considering the importance of literature, the present study concentrates on the equity sensitivity as independent for job attitudes. The study aims to assess and compare the levels of job gratification and commitment among benevolent, equity sensitive, and entitled. It was assumed that benevolent will report more job satisfaction and commitment compared to other categories. Male and female benevolent, equity sensitive and entitled will show different levels of job satisfaction and commitment.

\section{METHOD}

\section{Participants:}

Sample consisted of 300 employees (150 males, and 150 females) working in different organizations of Multan ranging in age from 25-55 years. Participants were more or less similar with education level. Sample was selected through convenience sampling technique.

\section{Instruments:}

Following instruments were utilized to gather information from employees. The relevance of the instruments was checked by a sample of 10 educationists. They were asked to examine carefully all the items of each instrument and rate which of them were relevant to the Pakistani culture. Analysis of the responses revealed that all the items were judged fairly relevant to the Pakistani culture. Translation of the instruments from English to Urdu was made by using the back translation method. The instruments were, then, administered to a sample of 50 employees so that their reliability and validity was determined.

\section{Equity Sensitivity Scale}

Equity sensitivity Scale (Sauleya \& Bedeian, 2000) comprising 16 items measure the three types of equity sensitivity classified as benevolent, equity sensitive, and entitled. It is a five points rating scale responding as strongly agree to strongly disagree scored between 1 to 5. The item no 8, 9, 11, 12, 13, 14, 15, and 16 are firstly scored reverse. Scores from 16 37 show Entitled, 38 - 58 show Equity Sensitive, and 59 - 80 show Benevolent.

\section{Job Satisfaction Survey}

The scale developed by Spector (1985) having 36 items measures employee postures and opinion about their job. It has nine sub-scales wherein each sub-scale is measured 
on four items with six point ratting scale. Items worded negatively are scored reverse. A total score is obtained by adding responses on all items. Total score can range from 36 to 216 with a cut score of 126.126 and above on the scale represent job satisfaction.

\section{Organizational Commitment Scale}

Organizational Commitment Scale (Meyer \& Allen, 1996) contains three dimensions: affective, continuance and normative. It has 17 items with 5-point ratting scale. The scores on three subscales show a total score of organizational commitment. Higher scores indicate higher commitment with organizations

\section{Procedure:}

Participants were selected through convenience sampling and approached at their work place. They were informed about the purpose of study. Equity Sensitivity Scale, Job Satisfaction Survey, and Organizational Commitment Scale were given to them with appropriate instructions. In case of any difficulty in understanding items, it was tried to make the statement clearer to them, so that they could give response accordingly. Finally, results were statistically analyzed with the use of SPSS.

\section{Results}

One Way Analysis of Variance (ANOVA) was performed for three categories of employees; benevolent, equity sensitive, and entitled to see the effect of equity sensitivity on their levels of job satisfaction and commitment. For the descriptive analysis, means and SD are exhibited in Table 1 and findings of ANOVA are depicted in Table 2.

Table 1 Differences in the scores of Job Satisfaction and Commitment of Benevolent, Equity Sensitive, and Entitled $(N=300)$

\begin{tabular}{|c|c|c|c|c|c|}
\hline \multirow{2}{*}{ Categories } & \multirow{2}{*}{$\mathrm{N}$} & \multicolumn{2}{|c|}{ Job Satisfaction } & \multicolumn{2}{c|}{ Organizational Commitment } \\
\cline { 3 - 6 } & & $\mathrm{M}$ & $\mathrm{SD}$ & $\mathrm{M}$ & $\mathrm{SD}$ \\
\hline Benevolent & 100 & 126.40 & 17.43 & 29.89 & 7.78 \\
\hline Equity Sensitive & 96 & 122.82 & 14.67 & 24.08 & 6.86 \\
\hline Entitled & 104 & 106.07 & 15.15 & 23.94 & 7.11 \\
\hline
\end{tabular}


Table 2 One Way Analysis of Variance for the Scores of Organizational Commitment and Job Satisfaction of Benevolent, Equity Sensitive, and Entitled $(N=300)$

\begin{tabular}{|c|c|c|c|c|c|c|}
\hline Scales & Source of Variation & SS & df & MS & F & P \\
\hline $\begin{array}{c}\text { Job } \\
\text { Performance }\end{array}$ & Between Groups & 475.031 & 2 & 237.516 & 4.627 & $.012^{*}$ \\
\hline & Within Groups & 5492.728 & 107 & 51.334 & & \\
\hline Total & 5967.759 & 109 & & & \\
\hline Jatisfaction & Between Groups & 326.304 & 2 & 163.152 & 4.875 & $.009^{*}$ \\
\hline & Within Groups & 3581.052 & 107 & 33.468 & & \\
\hline & Total & 3907.356 & 109 & & & \\
\hline
\end{tabular}

${ }^{*} \mathrm{P}<.05$

Table 1 and 2 show the significant differences among three types of employees in their levels of job satisfaction and commitment. Results indicate that mean score of job satisfaction and commitment is higher for benevolent. Scheffe-Test was computed to see the mean differences (Table 3).

Table 3 Multiple Comparisons for three Groups of employees; Benevolent, Equity Sensitive, and Entitled on the Organizational Commitment and Job Satisfaction

\begin{tabular}{|c|c|c|c|c|c|}
\hline & $\begin{array}{c}\text { Equity Sensitive } \\
\text { (i) }\end{array}$ & $\begin{array}{c}\text { Equity Sensitive } \\
\text { (j) }\end{array}$ & $\begin{array}{c}\text { Mean Difference } \\
(\mathrm{i}-\mathrm{j})\end{array}$ & $\begin{array}{c}\text { Standard } \\
\text { Error }\end{array}$ & $\mathrm{p}$ \\
\hline $\begin{array}{c}\text { Organizational } \\
\text { Commitment }\end{array}$ & Benevolent & Equity Sensitive & $3.2333^{*}$ & 1.7211 & $.02^{*}$ \\
\hline & $\begin{array}{c}\text { Benevolent } \\
\text { Equity Sensitive }\end{array}$ & Entitled & $-4.12 \mathrm{E}-02$ & 2.0103 & .08 \\
\hline & Benevolent & Equity Sensitive & 0.2108 & 1.5296 & $.01^{*}$ \\
Benevolent & Entitled & 3.1213 & .98 \\
\hline & Equity Sensitive & Entitled & -2.5135 & 2.6337 & .17 \\
\hline
\end{tabular}

${ }^{*} p<0.05$

Multiple Comparisons (Table 3) show the significant difference in the mean scores on job satisfaction and commitment between the two groups of benevolent and equity sensitive. It suggests that benevolent have higher level of job satisfaction and commitment. 
For the comparison of job satisfaction and commitment between male and female employees, t-test for independent sample was computed.

Table 4 Gender Differences in Organizational Commitment for the Scores of Benevolent, Equity Sensitive, and Entitled $(N=300)$

\begin{tabular}{|c|c|c|c|c|c|c|}
\hline Subordinates & Gender & $\mathrm{N}$ & M & SD & $t$ & $p$ \\
\hline \multirow[t]{2}{*}{ Benevolents } & Male & 62 & 61.13 & 3.15 & \multirow[t]{2}{*}{.063} & \multirow[t]{2}{*}{$.01^{*}$} \\
\hline & Female & 38 & 63.25 & 5.03 & & \\
\hline \multirow{2}{*}{ Equity Sensitives } & Male & 46 & 52.71 & 4.15 & 1.215 & .23 \\
\hline & Female & 50 & 52.66 & 4.76 & & \\
\hline \multirow{2}{*}{ Entitled } & Male & 58 & 57.32 & 2.30 & \multirow[b]{2}{*}{1.021} & \multirow[b]{2}{*}{$.03^{*}$} \\
\hline & Female & 46 & 53.50 & 251 & & \\
\hline
\end{tabular}

$\mathrm{df}=98,94,102,{ }^{*} \mathrm{p}<0.05$

Results (Table 4) are found to be significant as differences in male and female employees' level of commitment. Results suggest that benevolent females and entitled males show more commitment as compared to opposite groups. No gender differences were found in equity sensitive for their level of commitment.

Table 5 Gender Differences in Job Satisfaction for the Scores of Benevolent, Equity Sensitive, and Entitled $(N=300)$

\begin{tabular}{|c|c|c|c|c|c|c|}
\hline Subordinates & Gender & $\mathrm{N}$ & M & SD & $\mathrm{t}$ & $p$ \\
\hline \multirow{2}{*}{ Benevolent } & Male & 62 & 52.12 & 3.77 & \multirow[t]{2}{*}{-.063} & \multirow[t]{2}{*}{$.01^{*}$} \\
\hline & Female & 38 & 61.92 & 4.62 & & \\
\hline \multirow{2}{*}{ Equity Sensitive } & Male & 46 & 62.93 & 3.57 & 1.732 & .08 \\
\hline & Female & 50 & 63.61 & 3.10 & & \\
\hline \multirow{2}{*}{ Entitled } & Male & 58 & 54.01 & 4.05 & & \\
\hline & Female & 46 & 50.52 & 4.66 & 1.283 & $.04^{*}$ \\
\hline
\end{tabular}

$\mathrm{df}=98,94,102,{ }^{*} p<0.05$ 
Results (Table 5) are to be found significant differences in male and female employees' job satisfaction. Results suggest that benevolent females and entitled males show more job satisfaction as compared to opposite groups No gender differences were found in equity sensitive for their level of job satisfaction.

\section{Discussion}

Adams' Equity Theory (1965) refers to an unbiased harmony between a paid worker's contribution (effort, ability to do work, ability to endure hardships, excited interest, etc.) and a paid worker's yield (payment, advantages, and nonmaterial benefits such as appreciation, etc.). As determined by these scientific principles to explain this phenomenon, if this unbiased harmony is achieved, it leads to a healthy and fruitful association with the paid workers, which ultimately results in satisfied employees and gives them better incentives for effective performance.

This research explores the effects of equity sensitivity (the under reward and over reward situation) on the job satisfaction and commitment of employees working in organizations. The data were analyzed on the assumption that employees' perception that they are treated fairly or unfairly in their organizations will must affect the level of working, and satisfaction and commitment with their jobs.

The hypothesis that three categories of employees in terms of equity sensitivity i.e. benevolent, equity sensitive, and entitled will show different levels of commitment, and will have different degrees of job satisfaction due to the imbalance of their input and output, was supported by the current study (Table $1 \& 2$ ). The results are supported by the findings of Huseman et al. (1987) who proved that benevolent experience more fulfillments with their paid employment and remain stable in their working effectiveness at work place. These results are also in harmony with the research done by King and colleagues, (1993) who explained that benevolent are thought expectant greater tolerated of under-reward conditions compared to Equity Sensitive or Entitled. They also concluded that as related to other groups, benevolent report less discontent with their work when they get lower compensation than what is justified. They continue performing even in mentally painful state of affairs which in turn affect their commitment. Results of this study may assist to affirm the findings reported by Watson and Clark (1984) who found that reliable correlation exists among negative feelings like anxiousness, neuroticism, irritability, and equity sensitivity. Their research results show that equity sensitive and entitled feel more mental suffering, uneasiness, and discontentment in the long run that definitely affect their commitment. Judge (1993) also pointed out in his research with students that Benevolent and Equity Sensitive are greatly inclined to change their contributions and yield, and remain gratified as compared to Entitled when confronted by a situation when they get more compensation than what is justified. Whereas, compared to Benevolent, the Equity Sensitive and Entitled are more prone to behave according to their comparison to others and perform less when they get more compensation than what is justified.

Many studies have substantiated a strong relationship between equity sensitivity and other variables of importance for organizations. Speculative foundations prove a relation 
between equity sensitivity and job performance, and even the recent researches have discovered equity sensitivity to be a justifiable forecaster of job performance and commitment. The two field researches explained relying on observations that equity sensitivity may work together in forecasting job satisfaction and commitment (Mannix, Neale, \& Northcraft, 1995).

The present research is also geared to measure gender differences in the job commitment and job satisfaction of benevolent, equity sensitive, and entitled. Equity sensitivity is an important concept in the understanding of organizational behavior. When male and female employees are working in organization, they always have a perception about their efforts and outcomes in the form of pay, salary and rewards. The perception of both men and women employees working in organizations that either they are treated fairly or not, affects their level of commitment. Findings of the present research also indicated the same notion that benevolent females and entitled males show more job commitment and satisfaction as compared to opposite groups while both male and female equity sensitive report equal levels of job satisfaction and commitment. Results are in favor of the work by King and Hinson (1994) that found the gender differences in the attitudes towards job, and explored the effects of sex on commitment and satisfaction at work place.

\section{Conclusion}

The present study may be considered as a pioneering research in the area of organizational behavior in relation to three types of equity sensitivity; benevolent, equity sensitive, and entitled reacting towards their job satisfaction and commitment in Pakistani context. Notwithstanding the limitations of this study, the results revealed interesting cultural trends and perspectives from Pakistani sample. Based on the findings of present study it is concluded that benevolent have higher levels of commitment and satisfaction as compared to other groups. Results further suggested that benevolent females and entitled males show more job satisfaction and commitment as compared to other groups. No gender differences were found for equity sensitive group in their levels of job satisfaction and commitment.

\section{Limitations and Suggestions}

The study entails some limitations that should be considered while evaluating the research findings: Due to limited time and resources, the sample size was not large enough to represent the whole population. Convenience sampling technique, an approach of non probability, was used to select the sample which is another source of non representative sample. The study lacks external validity because the sample was specifically taken from the city of Multan, so it can not be generalized to whole population. So the present study invites the other researcher to conduct further studies with a representative larger sample from cities other than Multan. This study may well be replicated with some other demographic variables that could be more associated with the phenomenon of equity sensitivity and its effects on work attitudes. 


\section{References}

Adams, J. S. 1965. Inequity in social exchange. In L. Berkowitz (Ed.), Advances in Experimental Social psychology Newyork: Academic Press. 62:335-343.

Allen, N. J. \& Meyer, J. P. 1996. Affective, continuance and normative commitment to the organization: An examination of construct validity. Journal of Vocational Behaviour, Vol. 49: 252-276.

Cropanzano, R., James, K., \& Konovsky, M. (1993). "Dispositional Affect as a Predictor of Work Attitudes and Job Performance." Journal of organizational Behavior 14: 595-606.

Huseman, R.C., Hatfield, J.D. \& Miles, E.W. (1987). A New Perspective on Equity Theory: The Equity Sensitivity Construct. The Academy of Management Review. 12;2: 222-234.

Judge, T. 1993. "Does Negative Affectivity Moderate the Relationship Between Job Satisfaction and Voluntary Turnover?" Journal of Applied Psychology 3: 395-401.

King, W.C. \& Hinson, T. (1994) The influence of sex and equity on relationship preferences, assessment of opponent, and outcomes in a negotiation experiment, Journal of Management, 20, 605-24.

King, W.C., \& Miles, E.W. (1994). The measurement of equity sensitivity. Journal of Occupational and organizational Psychology, 67, 133-142.

King, W., Miles, E., \& Day, D.(1993). "A Test and Refinement of the Equity Sensitivity Construct.” Journal of Organizational Behavior. 67: 133-142.

Mannix, E., M. Neale, and G. Northcraft. 1995. "Equity, Equality, or Need? The Effects of Organizational Culture on the Allocation of Benefits and Burdens." Organizational Behavior and Human Decision Processes 3: 276-286.

Messick, D. \& Cook, K. (1983). Equity theory: psychological and sociological perspectives. Praeger, London.

Mueller, S. L. \& Clarke, L. D. (1998), Political- Economic context and sensitivity to equity: differences between the United States and the transition economics of central and Eastern Europe, Academy of Management Journal, 41, 379-29.

O' Neill, B. S., \& Mone, M. A. (1998). Investigating equity sensitivity as a moderator of relations between self-efficacy and work-place attitudes. Journal of Applied Psychology, 83 (5), 805-816.

Sauleya, K. S. \& Bedeian, A. G. (2000). "Equity sensitivity consturtion of a Measure and Examination of its Psychometric Properties." Journal of Management pp. 885-910.

Journal of Independent Studies and Research - MSSE

Volume 9

Number 1

January 201109 
Spector, P. E. (1985). Measurement of human service staff satisfaction: Development of the Job Satisfaction Survey. American Journal of Community Psychology, 13, 693-713.

Walster, E., Traupmann, J. \& Walster, G.W. (1978). Equity and Extramarital Sexuality. Archives of Sexual Behavior. 7;2: 127-142. Retrieved on 15 July, 2008, from "http://en.wikipedia.org/wiki/Equity_theory"

Watson, D., and L. Clark. 1984. "Negative Affectivity: The Disposition to Experience Aversive Emotional States." Psychological Bulletin 96: 465-490. 